and musculoskeletal pain one year later; and 3) to explore influences on expectations.

Methods A longitudinal cohort postal survey collected data about musculoskeletal pain and expectations at baseline and one year later among a cohort of workers in New Zealand $(n=$ 443). The postal survey was the New Zealand arm of the international CUPID (Cultural and Psychosocial Influences on Disability) study. Data were analysed descriptively and through multi-variable logistic regression. A qualitative study used indepth interviews to explore influences on expectations among a subset of participants $(n=14)$ with musculoskeletal pain who had taken part in the postal surveys.

Results Participants thought their pain could 'possibly,' 'probably' or 'definitely' be a problem in twelve months time for a high proportion of musculoskeletal pain reported in the baseline postal survey (69-88\% depending on the anatomical site). Those with poorer expectations were more likely to report musculoskeletal pain at the same anatomical site one year later. Multi-variable logistic regression showed that expectations at baseline were an independent factor associated with the persistence or recurrence of low back pain but not the other sites examined. Qualitative findings suggest that expectations are influenced by a range of factors including healthcare providers, the behaviour of symptoms and people's observations of others.

Conclusions A high proportion of participants thought their musculoskeletal pain would be a problem in the future and indeed for many people it was. Expectations appear to be influenced by a range of factors.

\section{PREVALENCE OF MUSCULOSKELETAL DISORDERS AMONG DENTAL PERSONNEL IN KHON KAEN PROVINCE, THAILAND}

R N Nithithamthada, Puntumetakul, Chaiklieng. Khon Kaen University, Khon Kaen, Thailand

\subsection{6/oemed-2013-101717.86}

Objective This cross sectional study was conducted to determine the prevalence of musculoskeletal disorders (MSDs) among government dental personnels in Khon Kaen Province of Thailand.

Methods There were 282 dental personnels enrolled into this study. Data were collected by interviews with the modified structural questionnaires. Descriptive statistics were used to describe characteristics and inferential statistics were MSDs prevalence and confidence interval (95\%CI).

Results The results showed that most participants were female (81.9\%), the minimum and maximum age were 20 years and 59 years, respectively (mean $=32.8 \pm 9.4$ years). Most participants had body mass index at normal level (18.5 $22.9 \mathrm{~kg} / \mathrm{m}^{2}$ ) for $55.3 \%$ Most positions were dental nurses (46.4\%), dentists (22.0\%) and patient assistants (18.1\%), respectively.

For the last 7-day and 1 month period the prevalence of MSDs were $61.7 \%(95 \% \mathrm{CI}=0.56-0.68)$ and $93.6 \%(95 \% \mathrm{CI}$ $=0.91-0.96)$, respectively. The highest prevalence at severe level of pain were found at areas of shoulder (24.6\%), lower back (19.3\%), and neck (16.7\%), respectively. Frequency of MSDs considering everyday occurrence found on areas of shoulder (13.6\%), neck (11.7\%), lower back (7.6\%), respectively. Among 264 MSDs cases of dental personnels, the report of pain impacted to daily activity was $76.1 \%$. The report of work was related-MSDs was $71.2 \%$. Symptoms was occurred at evening time after work $(41.3 \%)$. The intake of painkillers or treatment by Thai traditional medicine program was $64.6 \%$.

Conclusions The results identified neck-shoulder-back pain among dental personnels by showing the severity and the frequency of pain. Therefore there should be the health surveillance program of neck-shoulder-back pain among dental personnels. This findings are useful for the prospective cohortstudy to find out the risk factors for neck-shoulder-back pain among dental personnels.

\section{PREVALENCE AND RISK FACTORS OF LOW BACK PAIN AMONG INFORMAL GARMENT WORKERS IN THE NORTHEAST OF THAILAND}

${ }^{1} S$ Chaiklieng, ${ }^{2}$ Suggaravetsiri, ${ }^{3}$ Pultumetakul. 'Faculty of Public Health, Muang Khon Kaen, Thailand; '2Department of Epidemiology, Faculty of Public Health, Muang Khon Kaen, Thailand; ${ }^{3}$ Back, Neck and Other Joint Pain Research Group, Khon Kaen University, Muang Khon Kaen, Khon Kaen, Thailand

\subsection{6/oemed-2013-101717.87}

Objectives The cross-sectional analytic study was designed to investigate the prevalence of low back pain (LBP) and risk factors for LBP among informal garment workers.

Methods There were 446 garment workers in the Northeast of Thailand who entered into this study. Data was collected by the face-to-face interview with the structured questionnaires. The LBP prevalence was estimated. The associations between LBP and studied factors were identified by the univariate analysis and multiple logistic regression analysis. Risk factors were indicated by adjusted odds ratio $\left(\mathrm{OR}_{\mathrm{adi}}\right)$ and $95 \%$ confident interval $(95 \%$ $\mathrm{CI})$ at p-value $<0.05$.

Results Among 446 informal garment workers, most workers were female (94.84\%), mean of age was 37.64 years (S. D. = 6.85 ) and work experience was 10.61 years (S. D. $=7.53$ ). Most workers had the repetitive movement $(69.28 \%, 95 \% \mathrm{CI}=$ 64.98-73.58) and prolonged sitting of work $>8$ hours a day $(68.16 \%, 95 \%$ CI $=63.82-72.50)$. The six month-prevalence of LBP was $44.17 \%(95 \% \mathrm{CI}=39.54-48.80)$. The univariate analysis identified factors of gender, prolonged sitting, no change posture each hour and the repetitive task significantly associated with LBP. The multiple logistic regression analysis indicated that the significantly related factors to LBP were prolonged sitting $\left(\mathrm{OR}_{\mathrm{adj}}=\right.$ $2.11,95 \% \mathrm{CI}=1.27-3.50)$, no change posture each hour $\left(\mathrm{OR}_{\mathrm{adj}}\right.$ $=1.84,95 \% \mathrm{CI}=1.11-3.07)$, repetitive task $\left(\mathrm{OR}_{\mathrm{adj}}=1.97,95 \%\right.$ $\mathrm{CI}=1.18-3.30)$. Factor of male gender was correlated with LBP by protection $\left(\mathrm{OR}_{\mathrm{adj}}=0.31,95 \% \mathrm{CI}=0.11-0.89\right)$.

Conclusions The prevalence of LBP can identify heath impact of Thai informal garment workers. The risk factors of LBP consisted of personal, work characteristics, and work behaviours. Therefore, local health care units or administrative organisations should provide occupational health service and the health surveillance program among informal garment workers. The finding risk factors are very useful to apply for prevention of new cases of LBP.

\section{THE RELATIONSHIP BETWEEN OCCUPATIONAL STRESS, MUSCULOSKELETAL DISORDERS AND WORK ABSENCES: A COMPARATIVE STUDY BETWEEN ITALIAN AND} BRAZILIAN NURSING PERSONNEL

V E A F Felli. University of Sao Paulo - School of Nursing, Sao Paulo, Brazil

10.1136/oemed-2013-101717.88 
Objective Occupational stress (OS) has been associated with musculoskeletal disorders (MSKD) and related sickness absences, but the prevalence of MSKD deeply varies across countries and cultural/social variables and could influence their relationship with OS.

As part of the CUPID international study, we compared OS and MSKD in two groups of nursing personnel from Italian andBrazilianUniversityhospitals, countries characterised by different social background and economic environment.

Methods The CUPID Questionnaire and Effort Reward Imbalance Questionnaire (ERI) were administered to all subjects $($ Brazil $=150$, Italy $=311)$ to collect MSKD and related disability/absences, and the perceived OS. Data analysis considered the Wilcoxon's and Chi-square tests to compare answers across the countries, and multivariate logistic regression models to investigate the association between OS and MSKD.

Results The two population resulted comparables distribution of gender (female $=84 \%$ ). Italians reported more frequently to have been exposed to high physical workload in performing their daily job tasks.

In term of OS, Brazilian nurses reported a sensibly lower perceived "effort" and a higher "reward" (median ERI $=0.52$ vs. $0.63, p=0.001)$. In contrast, the prevalence of MSKD was comparable across countries (back and shoulder pain), but the frequency of MSKD-related absences in the last year (one week or more) was sensibly lower in Brazil (5\% vs. 12\%). Even if stress level were different, OS was associated to increased MSKD in both countries (Adj OR for an IQR ERI increase = 1.60 inItaly and OR $=4.14$ in Brazil, $\mathrm{p}<0.05$ for both).

Conclusions Reports of OS resulted very different in two groups, but its relationship with MSKD was present in both countries. The observed difference in MSKD-related absences prevalence had no significance.

\section{UPPER EXTREMITY MUSCULOSKELETAL PAIN IN LEBANESE BAKERY WORKERS}

R Habib. American University of Beirut, Beirut, Lebanon

\subsection{6/oemed-2013-101717.89}

Background Musculoskeletal (MS) pain in the upper extremities is a major cause of morbidity among workers in many occupations. Research links upper extremity pain of the shoulder, neck, wrists, and elbow with physical exertion in the workplace and psychosocial influences like workplace organisation. Lebanon's bakery industry is an important occupational environment to explore MS pain as it features cramped spaces, highly pressured work tasks, and frequent engagement of the upper extremities. Studies assessing musculoskeletal pain among workers are rare in Lebanon, as are studies of bakery workers from developing countries. This study assesses the magnitude of upper extremity musculoskeletal pain among Lebanese bakery workers and determines associations with physical and psychosocial variables.

Methods Surveys were conducted among 504 randomly selected bakeries across Lebanon between April and November of 2010. Samples were proportionate to the number of bakeries in each district of the country. Surveys were administered through faceto-face interviews at the workplace with the consent of employers and workers. The survey included items on musculoskeletal pain, general health, workplace activities and organisation, and socio-demographics. Descriptive and logistic regression analyses were completed using SPSS 20.0.
Results Almost 23\% of workers reported upper extremity pain. Workers reporting poor self-rated health or chronic illness were twice as likely to report painful symptoms, while workers holding a second job were also twice as likely to have MS pain. Workers engaging in tasks with their hands above their shoulders (OR: 2.58; CI: 1.45-4.58) or repeated wrist movements (OR: 2.68; CI: $1.07-6.70)$ were more likely to report MS pain.

Conclusions Physical exertions were correlated with upper extremity MS pain. These results indicate a need to focus future interventions on improving workplace ergonomic conditions and implement workplace safety training in Lebanese bakeries.

\section{WORK-RELATED MUSCULOSKELETAL DISORDERS AMONG WHITE-COLLAR WOMEN EMPLOYEES}

${ }^{1}$ H G Gül, ${ }^{2}$ Issever, 'Babaoglu, ${ }^{2}$ Hapçioglu. 'Istanbul, Turkey; ${ }^{2}$ Istanbul University, Istanbul, Turkey

\subsection{6/oemed-2013-101717.90}

Objectives Work-related musculoskeletal disorders (WMSDs) are one of major occupational health problem in developed and developing countries. WMSDs can affect all workers, but literature reviews indicate that women in general report more symptoms. We aimed in this study to evaluate the prevalence of work-related musculoskeletal disorders and possible risk factors among white-collar women workers in Istanbul, Turkey.

Methods The study design was self-reported questionnaire-based cross-sectional study. We collected personal and occupational information and musculoskeletal complaints of women who work in the service sector. We used modified version of a general standardised questionnaire including a picture of the body sites was used for analyses of perceived symptoms of MSDs. For different parts of the body, participants were asked to indicate whether they have had regular or long-lasting complaints. All data was coded for each of the parameters. A p $<0.05$ was considered statistically significant.

Results Questionnaires of 550 participants were completed and returned back for analysis. Five hundred seven (\%92.2) of female had an university graduate and more. In this study, the age range was between 23 and 60 years. Mean age was $34.77 \pm$ 5.71. MSD was increased with age and $(\mathrm{r}=0.127, \mathrm{p}=0.003)$. Twelve-month prevalence was $89.3 \%$ the most prevalent site affected was that of neck $(74.9 \%)$ followed by back $(74.2 \%)$ and waist $(65.8 \%)$ the least frequent disorder was that of elbows $(0.7 \%)$.

Conclusions The study confirms that white-collar women workers are at higher risk of musculoskeletal disorders. Our findings are similar to the results of the studies on this subject in developed countries. The associations of musculoskeletal disorders with gender and occupational risk factors should be considered especially. Prevention strategies of possible work place risk factors for women can reduce the prevalence of MSDs. It would be helpful to provide continuing education about ergonomic risks in the workplaces.

\section{ASSESSMENT OF TRAPEZIUS MUSCLE PARAMETERS AMONG SITTING AND STANDING WORKERS}

${ }^{1} \mathrm{O}$ K Oha, ${ }^{2}$ Pille, ${ }^{1}$ Merisalu, ${ }^{1}$ Pääsuke. ${ }^{1}$ University of Tartu, Viljandi, Estonia; ${ }^{2}$ Tallinn University of Technology, Tallinn, Estonia

10.1136/oemed-2013-101717.91 